\title{
13
}

\section{A GIS and SWMM Modeling Application for Sewer Separation Design}

\author{
Sharon Ho, Dominique Brocard, Lawrence Soucie and Thomas Daly
}

Partial or complete separation of combined sewers is one of the strategies that can be employed to control or eliminate combined sewer overflow (CSO) discharges. Separation of combined sewers can be expensive and disruptive to communities, since it involves digging up the street. In many urban areas, roof drains from houses are connected to sewers via downspouts (outside piping), or through roof leaders (internal plumbing). Disconnection of roof drainage connected to the sewer via internal plumbing can be very expensive and disruptive. In addition, experience has shown that it is very difficult to remove $100 \%$ of rainfall-induced inflow in a sewer. When storm drainage is removed from combined sewers, they become sanitary sewers carrying a small amount of residual inflow. The residual inflow may originate from a variety of sources such as leaky manholes, leaks in pipes, or building sump pumps. Quantification of this residual inflow is important since it affects the CSO activation frequency and thus the degree of roof drainage separation that must be undertaken to achieve CSO elimination goals.

Many hydrologic models employ coefficients to represent the directly connected impervious area (DCIA). These coefficients represent the fraction of the drainage basin that contributes flow to a drainage system. In general, this coefficient is proportional to the total amount of impervious area in the region. If sufficient geographic information and field data is available, it is possible to determine the contribution of runoff from different land-uses, and thus estimate the contribution of runoff from connected buildings to a combined system. This information in turn can be used for hydraulic modeling to estimate the

Ho, S., D. Brocard, L. Soucie and T. Daly. 2001. "A GIS and SWMM Modeling Application for Sewer Separation Design." Journal of Water Management Modeling R207-13. doi: 10.14796/JWMM.R207-13.

(C) CHI 2001 www.chijournal.org ISSN: 2292-6062 (Formerly in Models and applications to Urban Water Systems. ISBN: 0-9683681-4-X) 
number of buildings to disconnect to prevent the occurrence of CSOs. This chapter presents an application of this approach that was used for a sewer separation project in Boston.

\subsection{Study Area Description and Background}

The Stony Brook drainage basin is a 1,765 acre $\left(\sim 7.14 \mathrm{~km}^{2}\right)$ watershed located within the city limits of Boston, Massachusetts. Approximately 1,157 acres $\left(\sim 4.68 \mathrm{~km}^{2}\right)$ of this study area is considered separated, meaning that the storm water drainage network is separate from the sewer network. Rainfall in the remaining area enters the Boston Water and Sewer Commission's (BWSC) combined sewer system. A complicating factor is that much of the upstream separated area discharges to the combined system downstream. Therefore, inflow in the separated areas affects the CSO frequency. During storm events, storm water may overflow from the combined system into the storm drainage system through twelve CSO regulators in the project area. The CSOs discharge into the Stony Brook Conduit (SBC), which eventually discharges into the Charles River. A map of the study area can be found in Figure 13.1.

In 1987, the Massachusetts Water Resources Authority (MWRA) began the development of a plan to reduce pollution in Boston Harbor in compliance with a Federal Court Order resulting from the Clean Water Act. A CSO Facilities Plan developed by the MWRA in 1996 and 1997 used a SWMM model to estimate the number of CSOs in the Stony Brook area (MWRA, 1997). This plan estimated that the number of CSOs could be reduced from 22 to two or fewer during a typical year by separating the combined sewers. This approach was selected by the BWSC with the understanding that though two overflows would be permissible, zero annual overflows was the goal if economically feasible.

The general approach selected for sewer separation was to build a new storm drain network in the combined areas of Stony Brook to convey storm water runoff. Existing combined sewers would then be used to convey sanitary flow. Field crews would then disconnect building roof drains found to be connected to the former combined sewer system. However, it is generally impractical to disconnect all building roof drains in a drainage area. Some buildings are difficult to separate, for example, a building whose roof drains are interconnected with the building's plumbing. Sewer separation would then involve reworking the internal plumbing of these buildings, which would be both expensive and inconvenient. In these cases, building separation may not be performed. In addition, even if all the known sources of rainfall-induced inflow could be removed, there would still be a residual inflow that can influence 


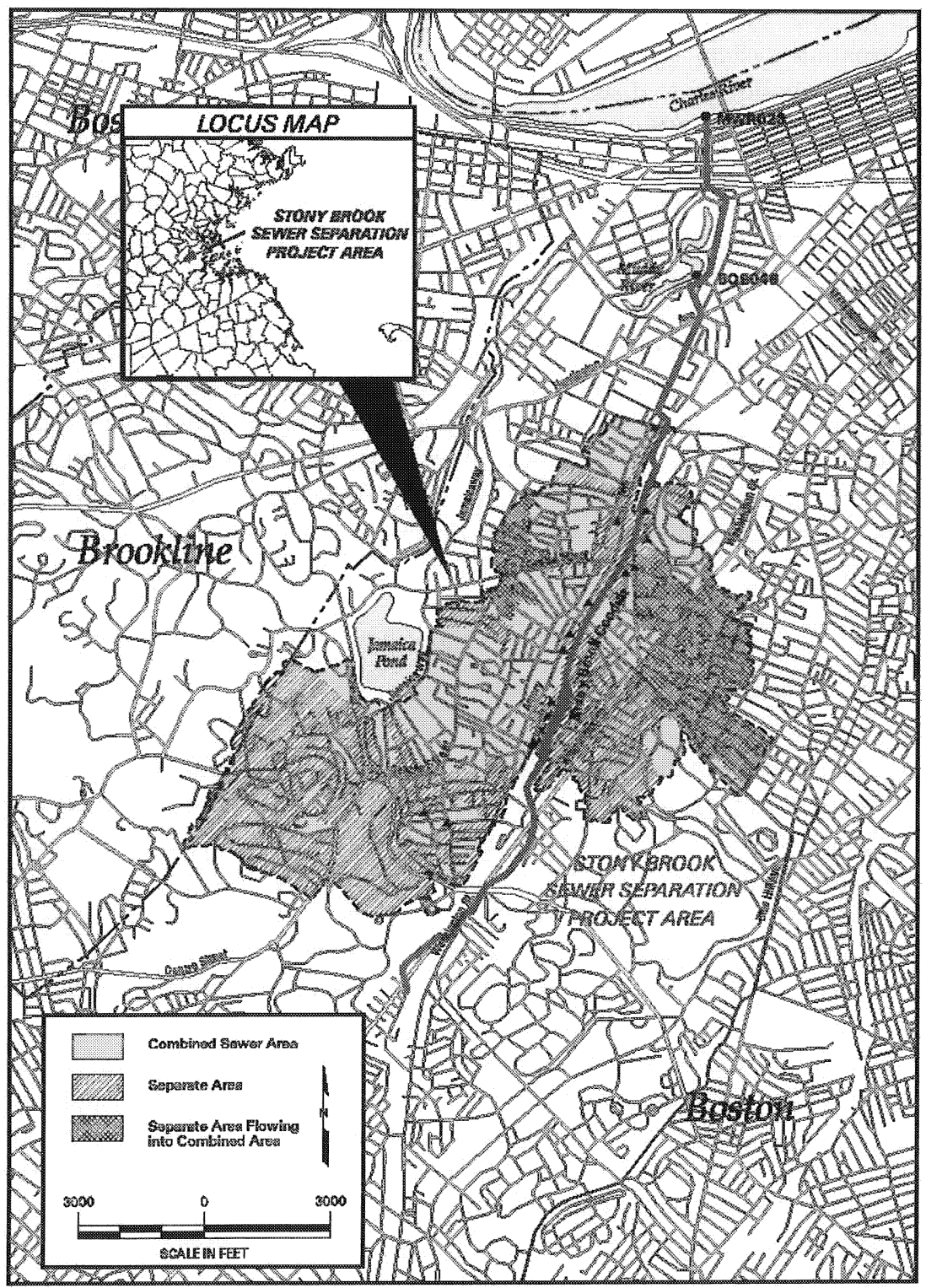

Figure 13.1 Plan of Stony Brook Project Area.

the CSO frequency and thus the number of buildings that must be disconnected. Therefore, a method was needed to estimate how many buildings should be disconnected to prevent $\mathrm{CSO}$ activation, taking into account the residual inflow. 
The purpose of this study was to combine the use of field data, geographic information system (GIS) analysis, and SWMM modeling to estimate the number of buildings to disconnect to meet the CSO activation goal.

To obtain the necessary data to complete the preliminary design, field data was collected and used to populate a GIS database. Specifically, it was necessary to know which buildings were connected to the sewer and how difficult it would be to disconnect them. The field work and database development is discussed in Sections 13.2 and 13.3. These data were then linked to the model so that the model accurately represented the system. It was also necessary to estimate the quantity of residual inflow that would remain after the sewer separation was complete. Model development and calibration are discussed in Section 13.4. Once the model was refined and linked to the database it could then be applied to determine the number of buildings that needed to be disconnected in order to reduce the number of CSOs to meet the goals. The application of the GIS database and model are described in Section 13.5

\subsection{Field Investigation}

As a first step, an extensive field investigation was implemented to identify sources of storm water flowing into the combined and sanitary sewer system. This program included performing inspections on approximately 5,700 buildings in the study area, $95 \%$ of which were residential. Buildings that were identified as having downspouts leading into the ground or into the building foundation were subjected to dye testing. Dyed-water tests were performed in separated areas to determine which buildings were connected to the sanitary system.

A limited number of tests were also performed in the combined areas. The overall results of the dyed-water tests were used to extrapolate which buildings were connected in the combined system. In general, it was assumed that $100 \%$ of the roof leaders and building downspouts leading into the foundation and $50 \%$ of the downspouts leading into the ground were connected to the combined sewer. All connected roof drains were classified as easy, moderate, or difficult to disconnect depending on their configuration.

Smoke tests were also performed on all the separated sanitary sewers to identify other inflow sources connected to the sanitary system. During these tests, nearly 100 catch basins were identified as being connected to the separated system, of these twenty were actually combined catch basins on the periphery of the combined sewer system. The tributary area to these catch basins was identified and measured. 


\subsection{GIS Database Development}

The Boston Water and Sewer Commission possesses an extensive GIS database for the city of Boston. This database includes coverages of Boston's storm water, sanitary, and combined systems as well as different land use features such as buildings, roads, parking lots, water bodies, wetlands, and topography. Before the field investigations began, it was decided that the building downspout information would be linked to the BWSC's GIS coverage of buildings in the Stony Brook area. Field crews used global positioning system (GPS) devices to measure latitude and longitude in front of each building after it was inspected. The GPS points were used to connect to the downspout and roof leader information to the appropriate building.

The drainage basin tributary to the SBC was divided into over 120 drainage subbasins for use in the hydraulic model. ARC/INFO GIS was used to calculate the area of easy, moderate, and difficult connections in each subbasin. Figure 13.2 summarizes these connected buildings in terms of acres tributary to the twelve CSO regulators that flow into the SBC.

The area of connected buildings was only a fraction of the total area tributary to these regulators. The GIS information provided by the BWSC was used to calculate the area of roads, parking lots, and total buildings in each subbasin. A summary of these GIS-calculated areas can be found in Table 13.1.

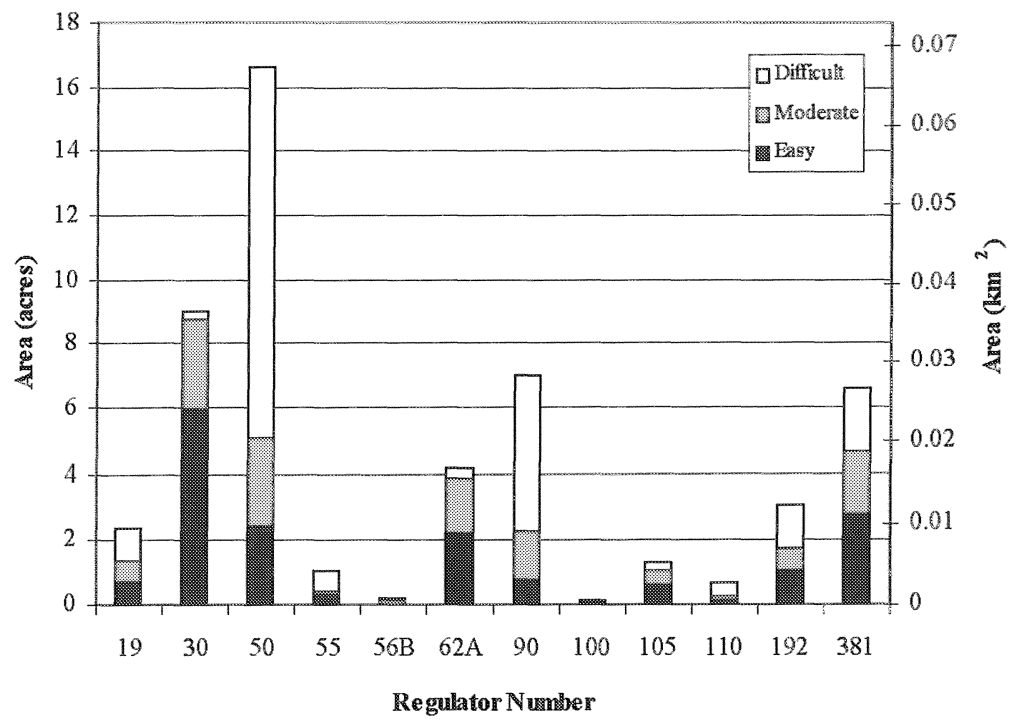

Figure 13.2 Connected building area tributary to CSO regulators in Stony Brook region. 
Table 13.1 Results of GIS analysis.

\begin{tabular}{lcc}
\hline & \multicolumn{2}{c}{ \% Impervious } \\
Impervious Feature & Combined Area & Separated Area \\
\hline Roads/Parking lots & 29.7 & 36.2 \\
Buildings & 20.3 & 13.9 \\
$\quad$ Easy to remove connected buildings & 1.3 & 1.0 \\
Moderately easy to remove connected buildings & 1.1 & 0.5 \\
Difficult to remove connected buildings & 1.6 & 0.8 \\
Total Percentage GIS-Calculated Impervious & 50.0 & 50.1 \\
\hline
\end{tabular}

\subsection{Model Development and Calibration}

As outlined in Section 13.2, an extensive amount of data was collected for this project. It was important to relate this data to the model so that it could be applied to compute the overflow frequency. BWSC's calibrated SWMM model of the Boston area was extended and refined to include sewers upstream of the CSO regulators. As part of this refinement, the percentage of DCIA for each drainage basin was estimated for the purposes of model re-calibration. One way to estimate this percentage for a drainage basin is to use metering data to develop rainfall-runoff regression curves. For small storms, the slope of the regression line divided by the tributary area should be an indicator of the DCIA in the basin, provided no upstream cross-connections or flooding exists (Doyle and Miller, 1980). Previously collected meter data at three locations were found to be suitable for the regression analysis. These meters were located in pipes leading to three of the regulators in the study area and contained flow from over $40 \%$ of the region. The percent DCIA for these tributary basins ranged from $8 \%$ in the separated areas to $30 \%$ in the combined areas. An example of a rainfall regression curve for one of the meters can be found in Figure 13.3.

The percentage of DCIA calculated through the rainfall-regression curves was related to the GIS-calculated area of roads, parking lots, connected, and non-connected buildings in each tributary basin (Table 13.2). The three metered basins represent very different areas in terms of separated and combined regions. The tributary area to one meter contained strictly combined area, while a second area was mostly separated. The third region contained a mixture of both separated and combined pipes.

The different drainage basins were analyzed to determine the "fractional DCIA coefficient" representing the contribution for runoff from different land use features. Because one of the areas was primarily separated, it was possible to estimate the amount of indirect inflow entering the sanitary system. The 


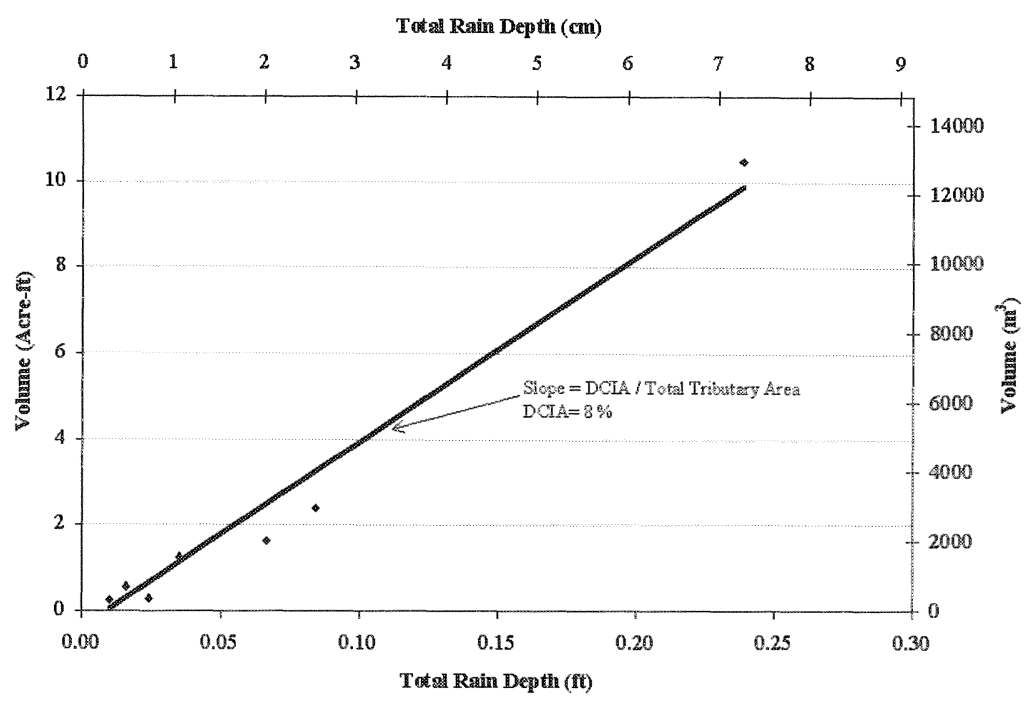

Figure 13.3 Rainfall-runoff regression curve.

contribution of inflow from building connections was estimated based on the results of the GIS analysis. Any additional flow from the separated region was attributed to other inflow sources. From analysis of the combined areas, it was determined that the fractional coefficient from connected buildings, roads, and parking lots would be approximately equal to $80 \%$, and would be $10 \%$ for nonconnected buildings based on their GIS-calculated area. If $80 \%$ of the connected building area contributed flow to the separated sewers, then an additional $5 \%$ of the overall separated area would be needed to achieve the flow measured through metering. Of this $5 \%, 1.25 \%$ was due to the direct inflow sources identified during smoke testing. The remaining $3.75 \%$ was attributed to sources of indirect inflow into the system such as defective pipe walls and joints.

Table 13.2 Percent of GIS-calculated area contributing runoff to regulators during storm events.

\begin{tabular}{lcc}
\hline \multirow{2}{*}{ Landuse Type } & \multicolumn{2}{c}{ Drainage Basin Type } \\
\cline { 2 - 3 } & Combined & Separated \\
\hline Connected building & $80 \%$ & $80 \%$ \\
Nonconnected building & $10 \%$ & --- \\
Roads/Parking Lots & $80 \%$ & --- \\
Other Direct Connections & --- & $1.25 \%$ \\
Residual Inflow & --- & $3.75 \%$ \\
\hline
\end{tabular}


Based on these results, the percent DCIA of the basins in combined areas would be $80 \%$ of the GIS-calculated road, parking lot, and connected building area, plus $10 \%$ of the nonconnected building area. In separated basins, the percentage would be $80 \%$ of the connected buildings plus $5 \%$ of the total separated tributary area. These calculations produced percentages that were very close to those obtained from the rainfall-runoff regression calculations, despite the fact that the three meters represented very different areas in terms of combined and separated regions. A summary of this analysis can be found in Table 13.3.

Table 13.3 Metered basin characteristics compared to estimations using fractional DCIA coefficients.

\begin{tabular}{cccc}
\hline Regulator & System Configuration & $\begin{array}{c}\text { Metered } \\
\% \text { DCIA }\end{array}$ & $\begin{array}{c}\text { Calculated } \\
\% \text { DCIA }\end{array}$ \\
\hline RE-046-55 & Combined & 30 & 29 \\
RE-046-62A & Mix of both & 15 & 16 \\
RE-046-30 & Mostly separated & 8 & 8 \\
\hline
\end{tabular}

Based on this analysis, the percent DCIA for each SWMM RUNOFF basin was calculated by applying the appropriate percentages on the GIS-calculated area. Separate basins were created for connected houses and indirect inflow, because flow from these sources will be delayed compared to the inflow from the roads and parking lots. Measured basin overland flow widths were adjusted until the measured flow hydrograph matched metered data during calibration storms. For basins representing direct house connections, the measured widths were divided by 10 , and the basins widths representing indirect flow connections were divided by 1000 .

Previous studies have demonstrated that reducing widths by large amounts to simulate delayed inflow significantly reduces the amount of water entering the system. Water in these basins has a longer time of travel, and therefore experience increased amounts of infiltration and evaporation (Brink and TenBroek, 1995). For this reason, the basins representing indirect inflow were placed in a separate RUNOFF block in which evaporation was turned off and the infiltration rates were high. This way, the quantity of flow entering the pipe due to delayed inflow in the model is known. The COMBINE block was used to combine the separate interface files.

After these adjustments were made, model output was compared to the metered data. An example calibration plot can be found in Figure 13.4. 


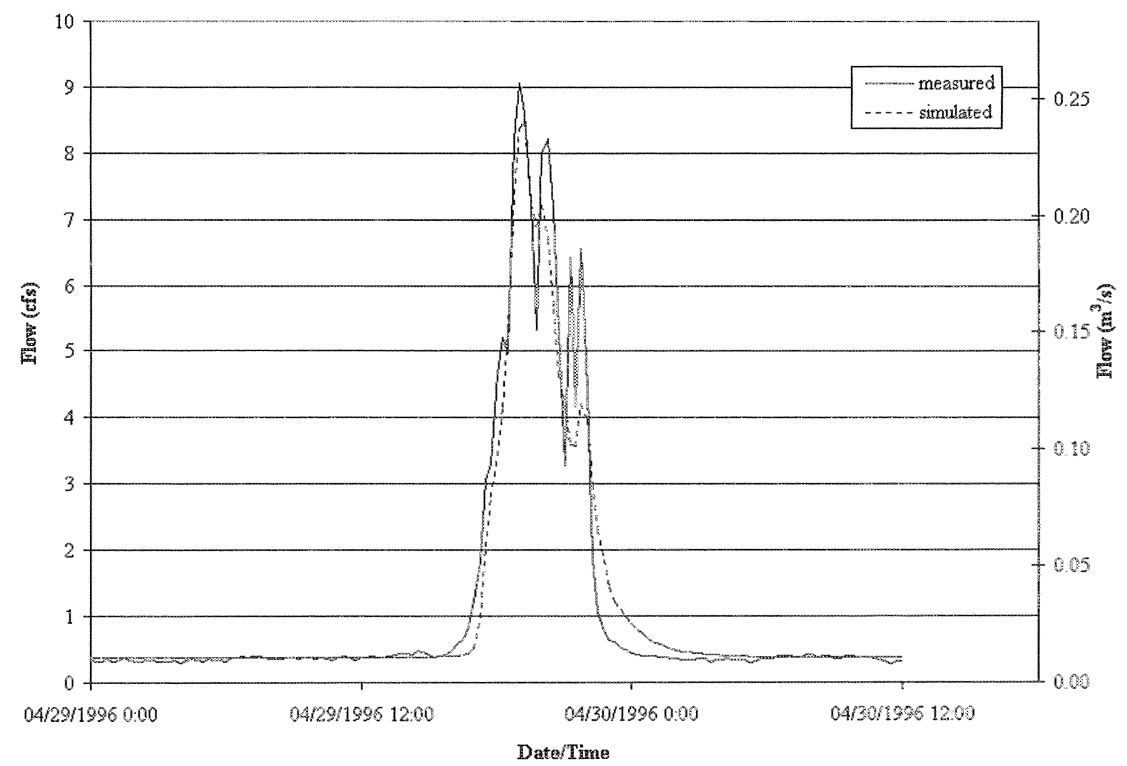

Figure 13.4 Comparison of measured and simulated flow.

\subsection{Model Application}

The calibrated SWMM model was then used to determine the effect of sewer separation on the number of overflows in the Stony Brook area. It was assumed that the sewer separation program would remove $100 \%$ of the flow contributed by the roads and parking lots and all of the easy and moderate building connections. This would leave the difficult building connections and the $3.75 \%$ of the basin area representing indirect inflow calculated during model calibration. To be conservative, it was assumed that $100 \%$ of the connected building area was contributing water to the combined system although calibration results indicated that this percentage is closer to $80 \%$. From this point, simulations were performed to determine the number of difficult building connections that would have to be removed to meet the BWSC's goal of two or fewer annual overflows.

A typical year of rainfall was developed as part of the MWRA CSO Facilities Plan Study, to provide a basis for annual estimates of CSO activation frequency and volume (MWRA 1994, 1995). The MWRA typical year was based on analysis of $40 \mathrm{y}$ of rainfall data from Logan International Airport in 
Boston, MA. The year 1992 was selected as the base year because 15-minute data was available. Storms were selectively added or removed from the 1992 rainfall period to better match the long-term average. The eight largest storms of this typical year were used to assess the effectiveness of varying degrees of separation in reducing or eliminating overflows. Characteristics of these eight storms can be found in Table 13.4.

Table 13.4 The eight largest storms of the MWRA typical year.

\begin{tabular}{cccccc}
\hline $\begin{array}{c}\text { Storm } \\
\text { No. }\end{array}$ & $\begin{array}{c}\text { Occurrence } \\
\text { Frequency }\end{array}$ & $\begin{array}{c}\text { Duration } \\
\text { (hours) }\end{array}$ & $\begin{array}{c}\text { Depth } \\
(\mathrm{cm})\end{array}$ & $\begin{array}{c}\text { Max. Intensity } \\
(\mathrm{cm} / \mathrm{hr})\end{array}$ & $\begin{array}{c}\text { Ave. Intensity } \\
(\mathrm{cm} / \mathrm{hr})\end{array}$ \\
\hline 1 & $>3$ month & 34 & 4.80 & 0.61 & 0.15 \\
2 & $<3$ month & 6 & 2.90 & 1.07 & 0.48 \\
3 & $>3$ month & 29 & 5.38 & 0.94 & 0.18 \\
4 & $<3$ month & 25 & 3.23 & 1.19 & 0.13 \\
5 & 1 year & 22 & 7.09 & 1.65 & 0.33 \\
6 & $>3$ month & 22 & 5.03 & 0.97 & 0.23 \\
7 & $>1$ year & 40 & 9.86 & 0.56 & 0.25 \\
8 & 2 year & 3 & 3.00 & 2.74 & 0.99 \\
\hline
\end{tabular}

Table 13.5 Overflow volume $\left(\mathrm{m}^{3}\right)$ during MWRA typical year storms as a function of percent difficult connections removed as predicted in SWMM.

\begin{tabular}{ccrrrr}
\hline $\begin{array}{c}\text { \% Difficult } \\
\text { Disconnected }\end{array}$ & $\begin{array}{c}\text { Regulator } \\
\text { RE-046- }\end{array}$ & \multicolumn{2}{c}{ Volume $\left(\mathrm{m}^{3}\right)$ by Typical Year Storm } & & \multirow{2}{*}{$\begin{array}{c}\text { Number of } \\
\text { Overflows }\end{array}$} \\
\cline { 2 - 5 } & & 1 & 5 & 8 & \\
\hline $0 \%$ & 50 & 120 & 283 & 500 & 3 \\
& 381 & 0 & 109 & 48 & 2 \\
\hline $10 \%$ & 50 & 87 & 166 & 407 & 3 \\
& 381 & 0 & 77 & 0 & 1 \\
\hline $20 \%$ & 50 & 55 & 62 & 315 & 3 \\
& 381 & 0 & 48 & 1 & 1 \\
\hline $30 \%$ & 50 & 0 & 0 & 223 & 1 \\
& 381 & 0 & 0 & 0 & 0 \\
\hline $40 \%$ & 50 & 0 & 0 & 134 & 1 \\
& 381 & 0 & 0 & 0 & 0 \\
\hline $50 \%$ & 50 & 0 & 0 & 54 & 1 \\
& 381 & 0 & 0 & 0 & 0 \\
\hline $60 \%$ & 50 & 0 & 0 & 0 & 0 \\
& 381 & 0 & 0 & 0 & 0 \\
\hline
\end{tabular}

No overflows occurred during typical year storms $2,3,4,6$, and 7 .

Model simulation results indicated that the minimum sewer separation (100\% removal of the parking and road area plus all the easy and moderate building connections) would eliminate overflows in all but two of the regulators. 
The percentage of difficult connections removed in the areas tributary to these two regulators was then increased to determine the degree of separation required to reduce the number of annual overflows during the typical year to two or fewer. The results of these simulations can be found in Table 13.5.

Further model simulations indicated that the $3.75 \%$ indirect inflow played a significant role in determining the level of disconnection required for sewer separation. This makes sense since the difficult building connections comprise $1.6 \%$ of the tributary area, which is of the same order as the indirect inflow. Without this indirect inflow, significantly fewer difficult connections would have to be removed to achieve 0 overflows during the typical year.

\subsection{Conclusions}

The purpose of this chapter was to present a methodology that could be used to link the results of field data stored in a database to the percent imperviousness used in the SWMM model. This procedure also provides an estimate of the residual inflow that would remain even after all known sources of inflow are removed. The methodology involved relating the percentage of directly connected impervious area calculated using GIS to values measured using flow monitoring for basins with different characteristics. For the area studied, excellent agreement between measured and estimated percentages was found by summing $80 \%$ of the GIS calculated roads, connected buildings, and parking lots, $10 \%$ of the GIS-calculated non-connected buildings, and $5 \%$ of the total separated area.

Once the percentage of DCIA was related to the database, it was possible to query the database to conduct what-if scenarios. For example, the database could be queried to calculate the percent DCIA that would result in a sub-basin if, say, $100 \%$ of the buildings with easily disconnected roof drains were removed. The model could then be run for a range of storms to estimate the overflow activation frequency for that particular alternative.

Application of this methodology involves an intensive amount of fieldwork to identify and categorize buildings with roof drainage connected to the sewer. If a sufficient understanding of the system is obtained, one can estimate the amount of residual inflow that will remain in the system after sewer separation is complete. For the area studied, residual inflow was about $3.75 \%$ of the total area. In other words, $3.75 \%$ of rainfall falling on the separated sewer area will get into sanitary sewers even if all known direct sources are removed. Identifying sources of direct inflow may be both complicated and time consuming. However without doing so, it will be difficult to assess the effects 
of sewer separation on a system. Without such detailed knowledge of the system, it is impossible to determine if CSO sewer separation will be effective until after construction is complete.

Although this procedure is sound, the results of this methodology have yet to be examined. Preliminary design of the separated system has only recently been completed, and construction is not expected to end until 2006 (BWSC, 1999). There are several possible reasons that the computed model results may not match what will be observed after separation. The shape of the inflow hydrograph after sewer separation may be different from pre-separation conditions. In addition, inflow has been shown to vary significantly within large drainage basins (Swarner and Thompson, 1994). Only three metered basins were used in the regression analysis presented in this chapter. Although these basins covered $40 \%$ of the tributary area, variations in infiltration may be present in other areas.

A post-separation monitoring program has been recommended to evaluate the effectiveness of the sewer separation project. Should this program be established, the effectiveness of this procedure will be further reviewed.

\section{References}

Boston Water and Sewer Commission. 1999. Stony Brook Separation Project BWSC Contract No. 98-206-003: Preliminary Design Report. Prepared for the BWSC by Metcalf and Eddy. October 1999.

Brink, P. and M.J. TenBroek. 1995. "Characteristic Width and Infiltration for Continuous SWMM." Journal of Water Management Modeling R183-17. doi: 10.14796/JWMM.R183-17.

Doyle, H.W. Jr. and J.E. Miller. 1980. Calibration of a Distributed Routing-Runoff Model at Four Urban Sites Near Miami, Florida in: Water-Resources Investigations 80-1, U.E. Geological Survey, NSTL Station, MS. February 1980.

Massachusetts Water Resources Authority. 1997. Final CSO and Facilities Plan and EIR. Prepared for the MWRA by Metcalf and Eddy. EOEA \# 10335. July 1997.

Massachusetts Water Resources Authority. 1995. System Master Plan Development of Flows. Prepared by the MWRA by Metcalf and Eddy. EOEA \# 10335. January 1995.

Massachusetts Water Resources Authority. 1994. System Master Plan and Combined Sewer Overflow (CSO) Control Plan. Prepared for the MWRA by Metcalf and Eddy. EOEA \# 10335. December 1994.

Swarner, Robert and Michael Thompson. 1994. Modeling Inflow and Infiltration in Separated Sewer Systems. Presented at WEFTEC '94, Water Environment Federation's 67th Annual Conference. Chicago, IL. October 1994. 